\title{
Medical students on the hospital ward: what do patients really think?
}

\author{
Authors: Rebecca Jeyaraj, ${ }^{\mathrm{A}}$ Anamika Kunnumpurath, ${ }^{\mathrm{A}}$ Ernest Soh, ${ }^{\mathrm{A}}$ Rhonda Trotman, ${ }^{\mathrm{A}}$ Annie Huckstep, ${ }^{\mathrm{A}}$ Harkiran \\ Sran, ${ }^{B}$ Elvin Chang, ${ }^{B}$ Joseph Newman, ${ }^{B}$ Matthew Camilleri, ${ }^{B}$ ] Paul Dilworth ${ }^{A}$ and Bimbi Fernando ${ }^{A}$
}

\section{Aims}

Interaction between students and patients is a universal and essential component of a high-quality medical education. However, little work has been done to assess the attitudes of inpatients towards medical students on the ward. This study thus aimed to elicit patients' thoughts on the role and impact of medical students in the inpatient setting.

\section{Methods}

A four-page questionnaire in English was developed and pre-tested for clarity among five inpatients in a large teaching hospital in London. From November-December 2017, 119 patients on all adult medical and surgical inpatient wards were approached using a systematic random sampling method. Eight patients were unable to complete the survey due to a language barrier, 19 patients were too frail and 15 patients declined to participate. Seventy-seven patients agreed to complete the questionnaire, with or without the help of a medical student. The study was registered as a clinical audit in accordance with the hospital research standards.

\section{Results}

The age of patients who completed the questionnaire ranged from 24-99 years; $56 \%$ were female, and 70\% had previously interacted with students in the hospital. Almost all (99\%) patients felt that it was important for the training of future doctors that medical students interact with inpatients during their hospital stay. In fact, $96 \%$ of patients felt that it was one of the roles of a medical student to learn by interacting with inpatients. Sixty percent of patients felt that medical students improve the quality of care, while $73 \%$ would like to have medical students involved in their future medical care. Of the patients who had previously interacted with medical students, $50 \%$ felt that students had positively influenced their time in hospital (Table 1) while $46 \%$ felt that they had made no difference.

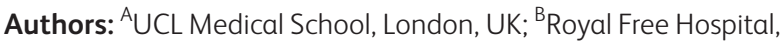
London, UK

\begin{tabular}{ll}
$\begin{array}{ll}\text { Table 1. Patients' reasons for students having a } \\
\text { positive influence on their hospital stay }\end{array}$ & $\%$ \\
\hline Reasons & 69 \\
Patients enjoyed the students company & 46 \\
Interacting with students helped to pass the time & 23 \\
Students helped convey information to the medical team & 15 \\
Students provided useful information & 12
\end{tabular}

\section{Conclusion}

Almost all patients felt that interaction with medical students was important and part of the student's role. In addition, a significant proportion feel that their clinical care and time in hospital are positively influenced by the presence of students. These results are reassuring for medical educators in secondary care settings. They are also particularly encouraging for medical students, many of whom feel apprehensive about approaching and interacting with inpatients in their early clinical years.

\section{Conflict of interest statement}

No conflicts of interest 